\title{
MÉTODO DE PREPARO DAS SEMENTES DE MAMONEIRA (Ricinus communis L.) PARA O TESTE DE TETRAZÓLIO ${ }^{1}$
}

\author{
CAROLINA MARIA GASPAR-OLIVEIRA²; CIBELE CHALITA MARTINS ${ }^{3}$; JOÃO NAKAGAWA ${ }^{4}$
}

\begin{abstract}
RESUMO - O teste de tetrazólio é um método rápido e eficaz para avaliar a viabilidade e o vigor de sementes. O presente trabalho teve por objetivo padronizar o método de preparo das sementes de mamoneira (Ricinus communis L.) para a avaliação do potencial fisiológico pelo teste de tetrazólio. Foram testados os seguintes métodos de preparo das sementes: corte longitudinal mediano através do tegumento, endosperma e embrião; corte longitudinal diagonal sem atingir o eixo embrionário; remoção do tegumento; remoção do tegumento com corte longitudinal mediano através do endosperma e embrião; e remoção do tegumento com corte longitudinal mediano, paralelo aos cotilédones, através do endosperma e embrião. Antes dos preparos, as sementes foram pré-condicionadas entre papel toalha umedecido por 18 horas a $30^{\circ} \mathrm{C}$, e após os preparos, as sementes foram imersas na solução de tetrazólio na concentração de $0,5 \%$ e mantidas em câmara escura a $35^{\circ} \mathrm{C}$ para o desenvolvimento da coloração. Avaliou-se a uniformidade da coloração das sementes após cada preparo, por meio da comparação entre eles. Para a avaliação do potencial fisiológico das sementes de mamoneira pelo teste de tetrazólio o método indicado de preparo é a remoção do tegumento, com posterior corte longitudinal e mediano, no sentido do comprimento, através do endosperma e embrião.
\end{abstract}

Termos para indexação: viabilidade, mamona, metodologia, tegumento.

\section{PREPARATION METHODS FOR THE CASTOR BEAN SEEDS (Ricinus communis L.) TETRAZOLIUM TEST.}

\begin{abstract}
The tetrazolium test is a quick and accurate method for estimating seed viability and vigor. This research had the objective of standardizing the preparation methods for castor bean seeds (Ricinus communis L.) to evaluate the physiological potential by the tetrazolium test. The evaluated seed preparation methods were: longitudinal cut through the middle of the seed coat, endosperm and embryo; longitudinal and diagonal cut without reaching the embryo; seed coat removal; seed coat removal with longitudinal cut through the middle of the endosperm and embryo; and seed coat removal with longitudinal cut parallel to the cotyledons through the middle of the endosperm and embryo. Before carrying out the preparation methods, the seeds were preconditioned between moist paper towels for 18 hours at $30^{\circ} \mathrm{C}$, and after preparation, the seeds were immersed in tetrazolium solution at $0.5 \%$ concentration and then placed in a dark chamber at $35^{\circ} \mathrm{C}$ for the staining development. The staining uniformity was evaluated after each preparation method by comparing the methods. It was concluded that the best seed preparation method was coat removal with a lengthwise longitudinal cut, through the middle of the endosperm and embryo.
\end{abstract}

Index terms: viability, methodology, seed coat.

${ }^{1}$ Submetido em 24/01/2008. Aceito para publicação em 19/09/2008. Parte da Tese de Doutorado do primeiro autor apresentada a UNESP/Faculdade de Ciências Agronômicas/Campus Botucatu.

²Eng. Agr. Dr., cmgasparol@gmail.com
${ }^{3}$ Eng. Agr. Dr. Professor colaboradora, Departamento de Produção Vegetal/ Agricultura, FCA/UNESP, cibele@fca.unesp.br

${ }^{4}$ Eng. Agr. Dr. Professor Titular voluntário, Departamento de Produção Vegetal/Agricultura, FCA/UNESP, secdamv@fca.unesp.br 


\section{INTRODUÇÃO}

A mamoneira (Ricinus communis L.) vem ganhando importância no cenário nacional devido principalmente ao Programa Brasileiro de Desenvolvimento Tecnológico do Biodiesel - PROBIODIESEL, que busca fontes alternativas de energia, capazes de substituir o petróleo. Esse programa criou um novo mercado para o óleo de mamona, que exigirá grandes áreas de plantio para atender a demanda de combustíveis. De acordo com o IBGE (2007), na safra 2006 a área plantada de mamoneira foi de 137.555 ha e, para 2007, há a previsão de colheita de 195.971 ha, o que representa uma demanda de 980 a 2000 toneladas de sementes.

Dessa maneira, a produção de sementes de mamoneira tem se apresentado cada vez mais tecnificada, com a participação de grandes empresas, produção de híbridos e valorização no preço. Portanto, a obtenção de informações precisas e completas sobre a qualidade das sementes produzidas tornase importante durante a produção e comercialização.

Entre os testes mais utilizados para avaliar a qualidade das sementes, destaca-se o teste de tetrazólio, pela sua rapidez, pois os resultados podem ser obtidos em aproximadamente 24 horas, e pela sua confiabilidade, comprovada na avaliação da qualidade de sementes de soja (França Neto et al., 1998), milho (Dias e Barros, 1999), café (Dias e Silva, 1998), feijãovagem (Bhering et al., 1996), amendoim (Bittencourt e Vieira, 1999), tomate (Santos, 2003), braquiária (Novembre et al., 2006) entre outras.

O teste de tetrazólio baseia-se na atividade de enzimas do grupo das desidrogenases, particularmente a desidrogenase do ácido málico, envolvidas na atividade respiratória das sementes, que catalisam a redução dos íons do sal de tetrazólio (cloreto de 2,3,5-trifenil tetrazólio) nos tecidos vivos. Íons de hidrogênio são transferidos para o sal de tetrazólio, que atua como um receptor desse elemento. O tetrazólio, que é um sal incolor e difusível é, então, reduzido a um composto não difusível de cor vermelha, conhecido por trifenilformazan, o que indica que as desidrogenases estão ativas, e consequentemente que há atividade respiratória nas mitocôndrias e, portanto, há viabilidade celular e do tecido (Delouche et al., 1976).

Assim, a coloração resultante da reação do tetrazólio é uma indicação positiva da viabilidade por meio da deteç̧ão da respiração das células. As sementes deterioradas ou danificadas mecanicamente desenvolvem rapidamente uma coloração vermelha-escura intensa e profunda, enquanto as vigorosas apresentam coloração rósea a vermelha e brilhante (Delouche et al., 1976; Bittencourt, 1995; França Neto et al., 1998). Por outro lado, nos tecidos mortos ou muito deteriorados as enzimas desidrogenases estão inativadas e por isso não ocorre a reação com o sal de tetrazólio e, consequentemente, a coloração dos tecidos (Marcos Filho et al., 1987).

Entretanto, o teste de tetrazólio ainda não tem uso generalizado para algumas espécies como a mamona, principalmente, devido à falta de treinamento de pessoal e à deficiência de conhecimentos sobre a metodologia adequada (Marcos Filho et al., 1987).

Diversos fatores podem interferir na obtenção de resultados satisfatórios no teste de tetrazólio, principalmente aqueles relacionados à metodologia de execução como preparo das sementes antes da coloração, concentração da solução de tetrazólio, período e temperatura de exposição à solução e critérios de interpretação.

O método de preparo das sementes depende das características da espécie em exame, sendo que os mais utilizados são: bissecção (ou corte) longitudinal, transversal ou lateral, puncionamento e remoção dos tegumentos. Esta etapa é necessária visando uma rápida, mas não brusca, penetração da solução de tetrazólio (Marcos Filho et al., 1987).

Sementes pequenas de leguminosas e de alguns outros gêneros não requerem preparo, podendo ser colocadas diretamente na solução de tetrazólio (França Neto et al., 1998). Outras espécies, no entanto, possuem sementes com tegumento espesso e duro que deve ser removido antes da coloração. É o caso de algumas espécies florestais como a sucará (Gleditschia amorphoides Taub.) (Fogaça et al., 2006) e o guapuruvu (Schizolobium parahyba Vell. Blake) (Ferreira et al., 2007).

Sementes de amendoim possuem o tegumento fino, entretanto, a remoção do mesmo antes da imersão das sementes na solução de tetrazólio possibilita a redução do período de coloração em cinco horas, além de permitir a utilização de solução de menor concentração (Bittencourt e Vieira, 1999). Em sementes de algodão e de melancia, é recomendado remover o tegumento anteriormente à imersão das sementes na solução de tetrazólio (Vieira e Von Pinho, 1999; Bhering et al., 2005). Para essas espécies, nos períodos de tempo estabelecidos, se os tegumentos não forem retirados não há absorção da solução de tetrazólio.

A remoção do tegumento após o pré-condicionamento, geralmente, possibilita maior uniformidade e rapidez no desenvolvimento da coloração. No entanto, esse procedimento pode prejudicar os resultados pela ocorrência de danos ao embrião durante a remoção (Marcos Filho et al., 1987; Vieira 
e Von Pinho, 1999).

Algumas espécies necessitam que seja realizado o corte da semente para a exposição do embrião e o contato direto desse com a solução de tetrazólio. Wetzel et al. (1992) recomendaram que após a embebição, as sementes de seringueira devem ser cortadas longitudinalmente, de forma paralela aos cotilédones. As sementes de diversas gramíneas como milho (Dias e Barros, 1999), trigo (Delouche et al., 1976), arroz (Dias e Shioga, 1997), braquiária (Novembre et al., 2006), entre outras, devem ser seccionadas longitudinal e medianamente através do embrião, pois o tetrazólio não penetra o pericarpo das gramíneas.

$\mathrm{Na}$ literatura encontram-se recomendações relacionadas ao preparo das sementes de mamoneira, indicando que esse pode ser realizado de diversas formas: corte longitudinal através do tegumento e do tecido de reserva, corte longitudinal diagonal evitando-se atingir o eixo embrionário, remoção ou separação da extremidade distal da semente, incluindo um fragmento do tecido de reserva (Brasil, 1992), ou remoção do tegumento (Grabe, 1976). Essas recomendações são restritas e imprecisas em função da carência de pesquisas relacionadas ao assunto, e as diferenças entre os métodos sugeridos acarretam dificuldades para o estabelecimento de padrões a serem seguidos.
As informações gerais para a realização do teste de tetrazólio de várias espécies estão indicadas nas Regras para Análise de Sementes (Brasil, 1992) e têm sido aprimoradas nos últimos anos, como pode se observar nos trabalhos de seringueira (Wetzel et al., 1992), amendoim (Bittencourt, 1995), soja (França Neto et al., 1998), milho (Dias e Barros, 1999), algodão (Vieira e Von Pinho, 1999), tomate (Santos, 2003), abobrinha (Barros et al., 2005), melancia (Bhering et al., 2005), braquiária (Novembre et al, 2006) entre outras espécies.

Assim, o objetivo deste estudo foi padronizar o método de preparo das sementes de mamoneira para a avaliação do potencial fisiológico pelo teste de tetrazólio.

\section{MATERIAL E MÉTODOS}

Avaliaram-se cinco métodos de preparo das sementes para o teste de tetrazólio, utilizando-se apenas um lote de sementes de mamoneira da variedade AL Guarany 2002, em duas repetições de 25 sementes para cada preparo, que estão descritos e ilustrados a seguir:

- Corte longitudinal mediano, no sentido do comprimento da semente, através do tegumento, endosperma e embrião (Figura 1a) (Brasil, 1992);
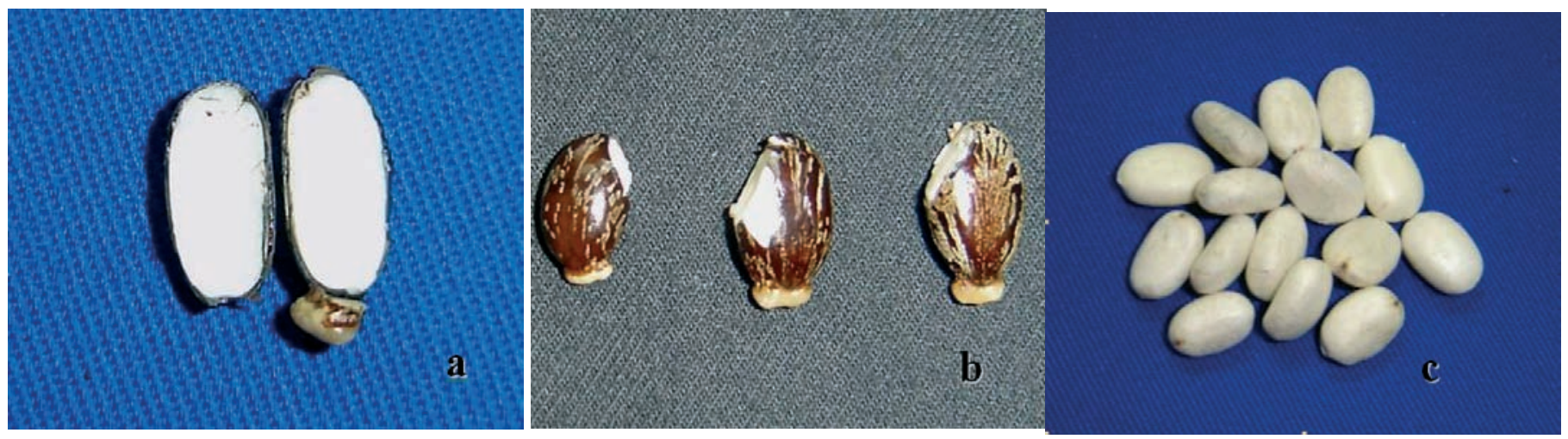

FIGURA 1. Métodos de preparo das sementes de mamoneira: corte longitudinal mediano, no sentido do comprimento da semente, através do tegumento, endosperma e embrião (a); corte longitudinal diagonal, no sentido da largura da semente, na região distal da carúncula, evitando-se atingir o eixo embrionário, através do tegumento, endosperma e embrião (b); remoção do tegumento (c).

- Corte longitudinal diagonal, no sentido da largura da semente, na região distal da carúncula, evitandose atingir o eixo embrionário, através do tegumento, endosperma e embrião (Figura 1b) (Brasil, 1992);

- Remoção do tegumento (Figura 1c) (Grabe, 1976);
- Remoçãodo tegumento, seguidadecortelongitudinal mediano, no sentido do comprimento da semente, através do endosperma e embrião (Figura 2a).

- Remoção do tegumento, seguida de cortelongitudinal mediano, no sentido da espessura da semente, 
paralelo aos cotilédones, através do endosperma e embrião (Figura 2b).

Antes dos preparos, as sementes foram pré-condicionadas entre papel toalha de germinação, previamente umedecido com 2,5 vezes a massa ( $\mathrm{g}$ ) do papel em água destilada, dobrado em quatro e colocado dentro de sacos plásticos de $0,05 \mathrm{~mm}$, para manter a umidade, por 18 horas a $30^{\circ} \mathrm{C}$ em câmara de germinação tipo B.O.D. (Moore, 1985; Brasil, 1992; França Neto et al., 1998).


FIGURA 2. Métodos de preparo das sementes de mamoneira: remoção do tegumento, seguida de corte longitudinal mediano, no sentido do comprimento da semente, através do endosperma e embrião (a); remoção do tegumento, seguido de corte longitudinal mediano, no sentido da espessura da semente, paralelo aos cotilédones, através do endosperma e embrião (b).

Os cortes e as remoções do tegumento foram realizados com o auxílio de bisturi e de lâmina de barbear. Após os preparos, as sementes foram imersas na solução de tetrazólio na concentração de $0,5 \%$ e mantidas em câmara escura a $35^{\circ} \mathrm{C}$ (Grabe, 1976). A uniformidade da coloração foi avaliada a cada hora até o período de duas horas, exceto para o método de preparo remoção do tegumento, cujo período de coloração foi de até seis horas, para permitir maior absorção da solução de tetrazólio pelas sementes.

Nos métodos de preparo mediante corte longitudinal diagonal evitando-se atingir o eixo embrionário e mediante remoção do tegumento, nos quais o embrião não estava exposto diretamente à solução de tetrazólio, para a avaliação da parte interna da semente, realizou-se o corte longitudinal mediano através do embrião, após o período de coloração.

Na avaliação do melhor método de preparo para o teste de tetrazólio em sementes de mamoneira, considerou-se aquele que proporcionou o desenvolvimento da coloração mais nítida para as sementes, sendo esse parâmetro avaliado visualmente por comparação entre os métodos. Assim, nesse trabalho, não foi realizada análise estatística.

\section{RESULTADOS E DISCUSSÃO}

Os preparos da semente mediante corte longitudinal mediano, no sentido do comprimento e da espessura, através do endosperma e embrião com e sem a remoção do tegumento (Figura 3) favoreceram o contato da parte interna da semente com a solução de tetrazólio, resultando em uma coloração uniforme de todo o embrião e endosperma. Entretanto, o preparo sem a remoção do tegumento (Figura 3b) causou danos ao embrião e, em alguns casos, destruição do eixo hipocótilo-radícula, devido à pressão exercida pela lâmina para ultrapassar o tegumento da semente no corte. Já, o preparo pela remoção do tegumento, seguida de corte longitudinal mediano, no sentido da espessura, através do endosperma e embrião (Figura 3c) causou danos aos cotilédones, pois os mesmos estão fortemente aderidos, o que causou dificuldade em separá-los. Esses danos ao embrião dificultaram a identificação de injúrias pré-existentes, assim como a avaliação correta da viabilidade. Fogaça (2003) também observou ocorrência de danos em sementes de guaritá (Astronium graveolens Jacq.), devido à presença do tegumento no momento do corte da semente. 

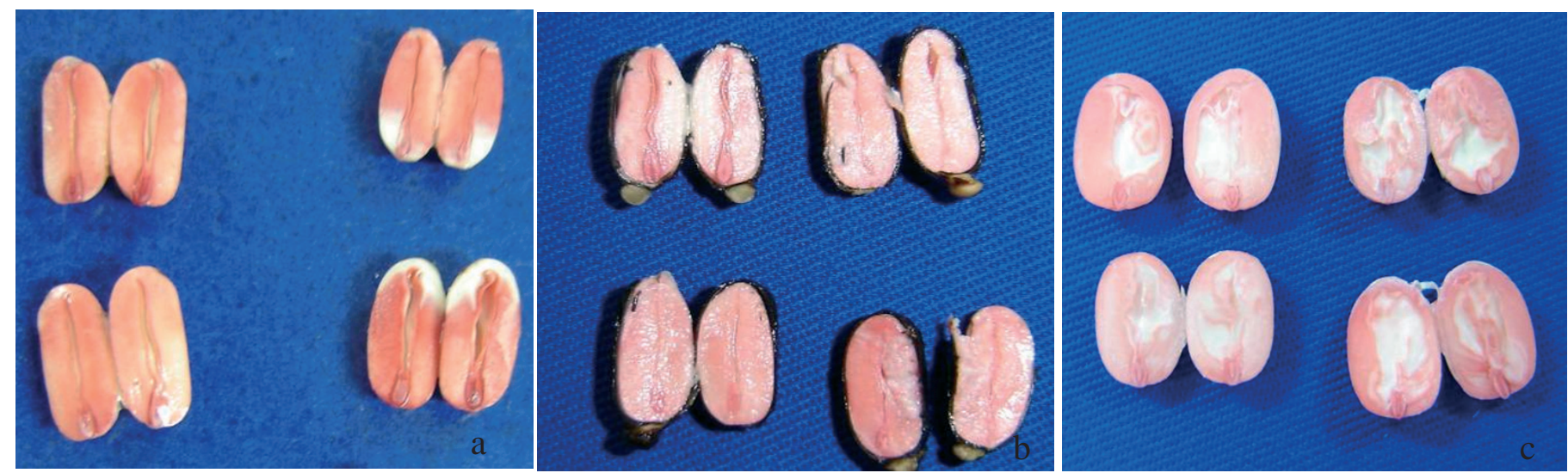

FIGURA 3. Sementes de mamoneira após a imersão no tetrazólio, preparadas mediante corte longitudinal mediano, no sentido do comprimento, através do endosperma e embrião com (a) e sem (b) a remoção anterior do tegumento; e mediante remoção do tegumento, seguido de corte longitudinal mediano, no sentido da espessura, paralelo aos cotilédones, através do endosperma e embrião (c).

Nos preparos mediante corte longitudinal diagonal na região distal da carúncula evitando-se atingir o eixo embrionário (Figura 4) e mediante remoção do tegumento (Figura 5), as sementes não apresentaram coloração na região central do tecido de reserva e no embrião. Somente as regiões periféricas das sementes, que tiveram contato direto com a solução de tetrazólio, ficaram coloridas. No caso do preparo mediante remoção do tegumento, mesmo após seis horas imersas na solução de tetrazólio (Figuras 5c e 5d), as sementes apresentaram embrião e endosperma sem coloração. Considerando que o embrião está localizado na parte interna da semente e é a principal estrutura a ser analisada na avaliação da viabilidade e do vigor no teste de tetrazólio, esses métodos de preparo mostraram-se ineficientes.
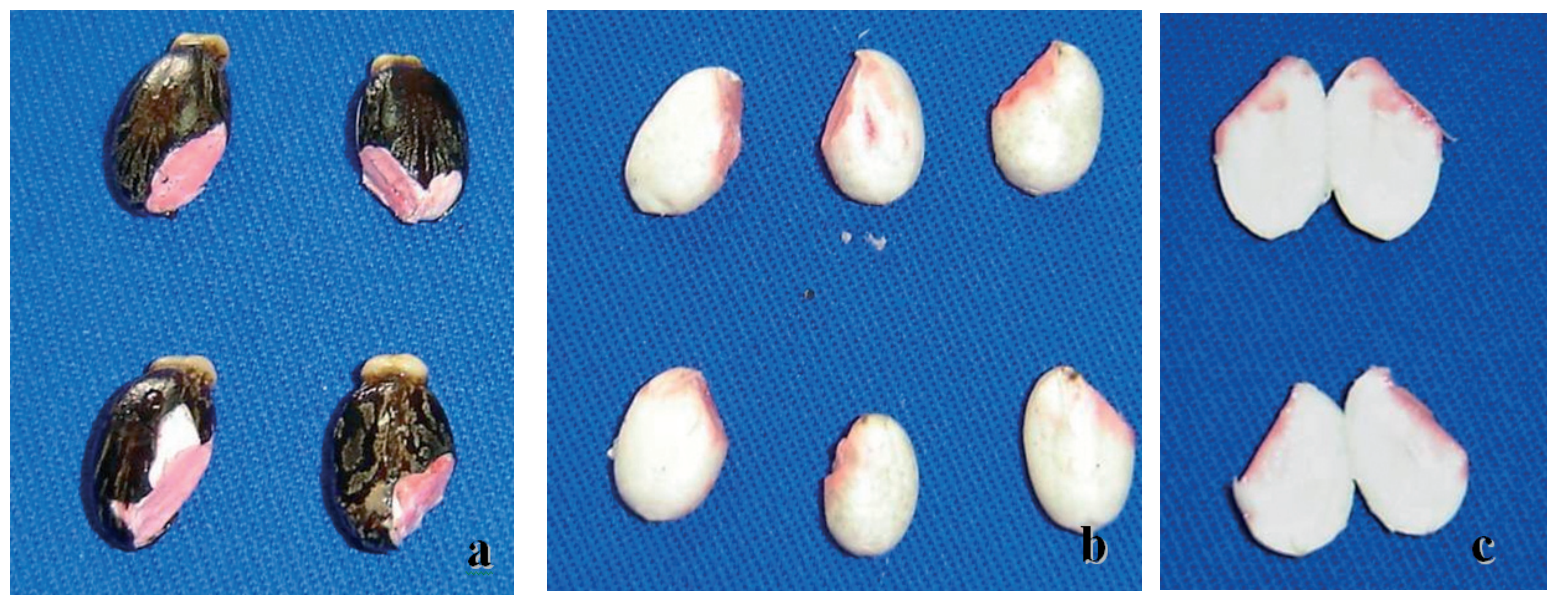

FIGURA 4. Sementes de mamoneira após a imersão no tetrazólio, preparadas mediante corte longitudinal diagonal na região distal da carúncula evitando-se atingir o eixo embrionário: com tegumento (a); após a retirada do tegumento (b); e após corte longitudinal mediano através do embrião (c).

Além disso, no preparo mediante corte longitudinal diagonal na região distal da carúncula evitando-se atingir o eixo embrionário, após a imersão na solução de tetrazólio, o endosperma amolece e a semente aumenta de tamanho, dificultando a remoção do tegumento na avaliação, o que pode causar danos às sementes (Figura 4). Por essa razão, não foram testados períodos maiores que duas horas para esse método. 

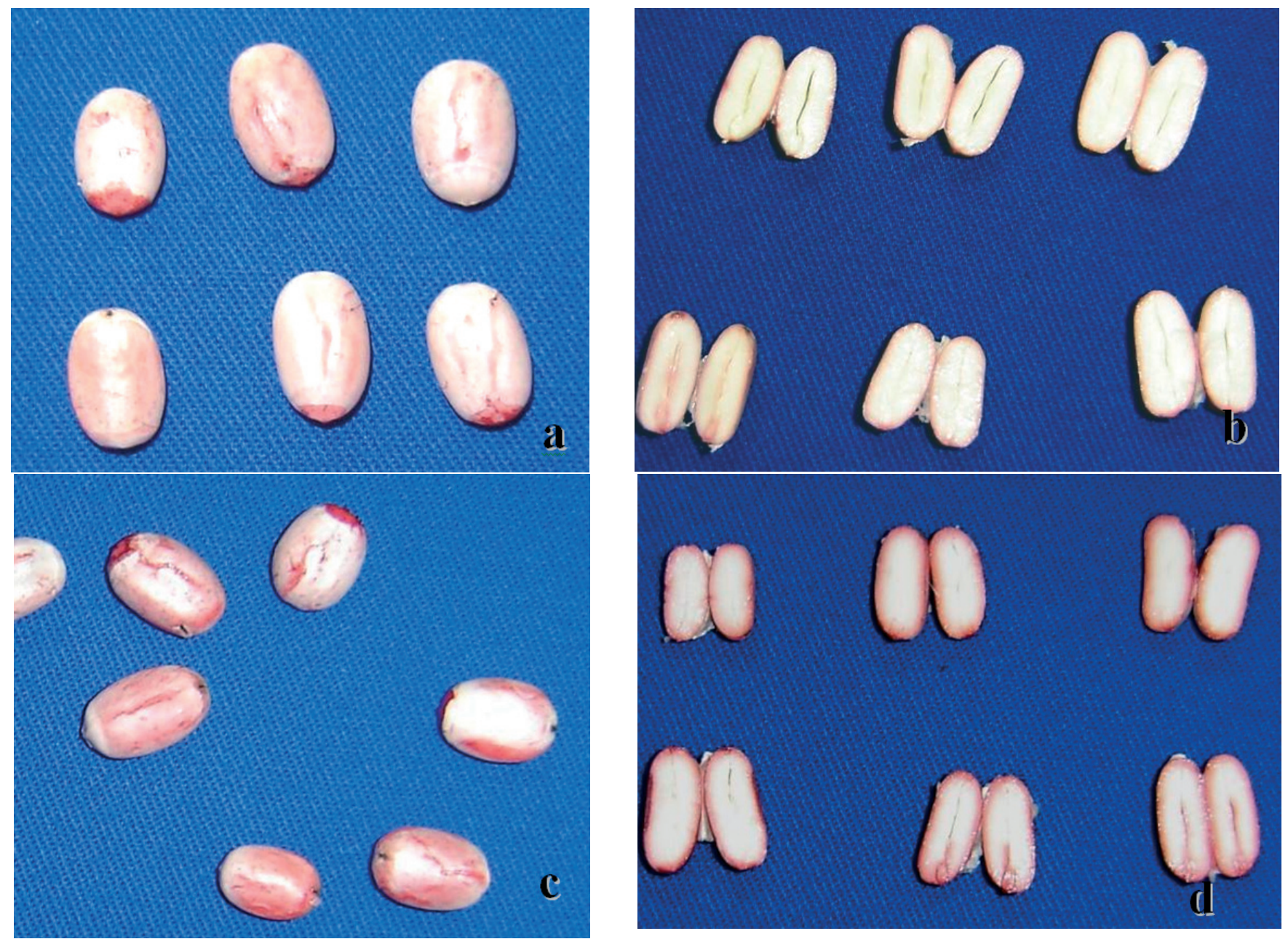

FIGURA 5. Sementes de mamoneira preparadas mediante remoção do tegumento, após duas horas de imersão no tetrazólio: sementes intactas (a); sementes após corte longitudinal mediano através do embrião (b); e após seis horas de imersão no tetrazólio: sementes intactas (c); e após corte longitudinal mediano através do embrião (d).

Nos períodos de coloração empregados nesta pesquisa, o tegumento e o endosperma não permitiram a difusão da solução de tetrazólio até o embrião. Portanto, no preparo das sementes para o teste o tegumento deve ser removido e as sementes devem ser cortadas longitudinal e medianamente através do endosperma e embrião antes de serem submetidas à coloração.

Os resultados observados neste estudo discordam das Regras para Análise de Sementes (Brasil, 1992) e de Grabe (1976), pois os métodos de preparo indicados por esses autores para mamoneira não proporcionaram coloração adequada das sementes, dificultando a diferenciação dos tecidos e a avaliação da qualidade das sementes pelo teste de tetrazólio.

A remoção do tegumento das sementes de mamoneira após a embebição e antes da coloração, embora seja uma operação relativamente delicada e trabalhosa, possibilitou considerável facilidade no corte, não danificando as sementes, e permitindo a correta avaliação da viabilidade pelo teste de tetrazólio. A necessidade da remoção do tegumento, como parte do preparo das sementes antes da coloração, também foi relatada para sementes de amendoim (Bittencourt e Vieira, 1999), algodão (Vieira e Von Pinho, 1999), melancia (Bhering et al., 2005), seringueira (Wetzel et al., 1992), sucará (Fogaça et al., 2006), guapuruvu (Ferreira et al., 2007) e guaritá (Fogaça, 2003).

O corte longitudinal mediano antes da coloração (Figura 3) possibilitou o contato direto dos tecidos internos (embrião e endosperma) com a solução de tetrazólio e a coloração das regiões vitais da semente. A exposição do embrião 
diretamente na solução de tetrazólio também é necessária para o desenvolvimento de uma coloração adequada em sementes de milho (Dias e Barros, 1999), trigo (Delouche et al., 1976), arroz (Dias e Shioga, 1997), seringueira (Wetzel et al., 1992), tomate (Santos, 2003), braquiária (Novembre et al., 2006), entre outros.

A coloração do endosperma no teste de tetrazólio não é comum, mas foi verificada nas sementes de mamoneira. Nessa espécie, o endosperma é um tecido vivo, e contém proteínas em forma de grãos de aleurona que secretam enzimas hidrolíticas (Carvalho e Nakagawa, 2000). Esse fato também foi observado em sementes de seringueira, embora, para essa espécie, o preparo recomendado seria o corte longitudinal paralelo aos cotilédones (Wetzel et al., 1992).

Portanto, o método de preparo das sementes de mamoneira para o teste de tetrazólio que apresentou os melhores resultados foi o de remoção do tegumento seguida de corte longitudinal mediano, no sentido do comprimento da semente, através do endosperma e embrião.

\section{CONCLUSÕES}

Para a avaliação do potencial fisiológico das sementes de mamoneira pelo teste de tetrazólio o melhor método de preparo é a remoção do tegumento, com posterior corte longitudinal e mediano, no sentido do comprimento, através do endosperma e embrião.

\section{REFERÊNCIAS}

BARROS, D.I.; DIAS, D.C.F.S.; BHERING, M.M.; DIAS, L.A.S.; ARAÚJO, E.F. Uso do teste de tetrazólio para avaliação da qualidade fisiológica de sementes de abobrinha. Revista Brasileira de Sementes, v.27, n.2, p.165-171, 2005.

BHERING, M.C.; SILVA, R.F.; ALVARENGA, E.M.; DIAS, D.C.F.S.; PENA, M.F. Avaliação da viabilidade e do vigor das sementes de feijão-de-vagem (Phaseolus vulgaris L.) pelo teste de tetrazólio. Viçosa: UFV, 1996. 27p.

BHERING, M.M.; DIAS, D.C.F.S.; BARROS, D.I. Adequação da metodologia do teste de tetrazólio para avaliação da qualidade fisiológica de sementes de melancia. Revista Brasileira de Sementes, v.27, n.1, p.176-182, 2005.

BITTENCOURT, S.R.M.de. Avaliação da qualidade fisiológica de sementes de amendoim através do teste de tetrazólio. 1995. 111 f. Dissertação (Mestrado em Agronomia) - Faculdade de Ciências Agrárias e Veterinárias - Universidade Estadual Paulista, Jaboticabal.

BITTENCOURT, S.R.M.de.; VIEIRA, R.D. Metodologia do teste de tetrazólio em sementes de amendoim. In: KRZYZANOWSKI, F.C.; VIEIRA, R.D.; FRANÇA NETO, J.B Vigor de sementes: conceitos e testes. Londrina: ABRATES, 1999. cap.8, p.2.1-2.8

BRASIL, Ministério da Agricultura e Reforma Agrária. Regras para análise de sementes. Brasília, DF: SNDA/ DNDV/CLV, 1992. 365p.

CARVALHO, N.M.; NAKAGAWA, J. Sementes: ciência, tecnologia e produção. 4 ed. Jaboticabal: Funep, 2000. 588p.

DELOUCHE, J.C.; STILL, T.W.; RASPET, M.; LIENHARD, M. O teste de tetrazólio para viabilidade da semente. Brasília, DF: AGIPLAN, 1976. 103p.

DIAS, M.C.L.L.; BARROS, A.S.R. Metodologia do teste de tetrazólio em sementes de milho. In: KRZYZANOWSKI, F.C.; VIEIRA, R.D.; FRANÇA NETO, J.B.Vigor de sementes: conceitos e testes. Londrina: ABRATES, 1999. cap.8, p.4.1-4.10.

DIAS, M.C.L.L.; SHIOGA, P.S. Tratamentos para superar a dormência em sementes de arroz (Oryza sativa L.). Revista Brasileira de Sementes, v.19, n.1, p. 52-57, 1997.

DIAS, M.C.L.L.; SILVA, W.R. Teste de tetrazólio em sementes de café. Londrina: IAPAR, 1998, 16p. (Boletim Técnico n.59).

FERREIRA, R.A.; OLIVEIRA, L.M.; TONETTI, O.A.O.; DAVIDE, A.C. Comparação da viabilidade de sementes de Schizolobium parahyba (Vell) Blake - Leguminosae Caesalpinaceae, pelos testes de germinação e tetrazólio. Revista Brasileira de Sementes, v.29, n.3, p. 83-89, 2007.

FRANÇA NETO, J.B.; KRZYZANOWSKI, F.C.; COSTA, N.P. da. O teste de tetrazólio em sementes de soja. Londrina: EMBRAPA-CNPSo, 1998. 72p.

FOGAÇA, C.A. Padronização do teste de tetrazólio para a avaliação da viabilidade de sementes de três espécies florestais. 2003. 53 f. Dissertação (Mestrado em Agronomia) - Faculdade de Ciências Agrárias e Veterinárias - Universidade Estadual Paulista, Jaboticabal. Disponível em: <http://www.athena.biblioteca.unesp.br $>$ Acesso em: 23 fev. 2005.

FOGAÇA, C.A.; ZUCARELI, C.; MALAVASI, M.M.; ZUCARELI, C; MALAVASI, U.C. Aplicação do teste de tetrazólio em sementes de Gleditschia amorphoides Taub. 
Caesalpinaceae. Revista Brasileira de Sementes, v. 28, n. 3, p.101-107, 2006.

GRABE, D.F. Manual do teste de tetrazólio em sementes. Brasília, DF: AGIPLAN, 1976. 86p.

IBGE. Levantamento sistemático da produção agrícola. Disponível em: <http://www.ibge.gov.br/home/estatistica/ indicadores/agropecuaria/lspa/lspa_200705_4.shtm> Acesso em: 16 abr. 2007.

MARCOS FILHO, J.; CÍCERO, S. M.; SILVA, W. R. Avaliação da qualidade das sementes. Piracicaba: FEALQ, 1987. 230p.

MOORE, R.P. Handbook on tetrazolium testing. Zurich: ISTA, 1985, 99p.

NOVEMBRE, A.D.L.C.; CHAMMA, H.M.C.P.; GOMES, R.B.R. Viabilidade das sementes de braquiária pelo teste de tetrazólio. Revista Brasileira de Sementes, v.28, n.2, p.147151, 2006.

SANTOS, M.A.O. Avaliação do potencial fisiológico de sementes de tomate através do teste de tetrazólio. 2003. 68 f. Dissertação (Mestrado em Agronomia) - Escola Superior de Agricultura "Luiz de Queiroz" - Universidade de São Paulo, Piracicaba. Disponível em: $<\underline{\text { http://www.teses.usp.br/ }}$ teses/disponiveis/11/11136/tde-11072003-134102/> Acesso em: 25 fev. 2005.

VIEIRA, M.G.G.C.; VON PINHO, E.V.R. Metodologia do teste de tetrazólio em sementes de algodão. In: Vigor de sementes: conceitos e testes. KRZYZANOWSKI, F.C.; VIEIRA, R.D.; FRANÇA NETO, J.B. Londrina: ABRATES, 1999. cap.8, p.1.1-1.13.

WETZEL, M.M.V.S.; CÍCERO, S.M.; FERREIRA, B.C.S. Aplicação do teste de tetrazólio em sementes de seringueira. Revista Brasileira de Sementes, v.14, n.1, p.83-88, 1992. 